\title{
Luciferase fragment complementation imaging in preclinical cancer studies
}

\author{
Madryn C. Lake $^{1}$ and Eric O. Aboagye ${ }^{1}$ \\ ${ }^{1}$ Comprehensive Cancer Imaging Centre, Faculty of Medicine, Imperial College London, Hammersmith Hospital, London \\ Correspondence to: Eric O. Aboagye, email: eric.aboagye@imperial.ac.uk \\ Keywords: Luciferase, Imaging, Cancer \\ Received: May 12,2014 Accepted: May 31, $2014 \quad$ Published: June 1, 2014
}

This is an open-access article distributed under the terms of the Creative Commons Attribution License, which permits unrestricted use, distribution, and reproduction in any medium, provided the original author and source are credited.

\section{ABSTRACT:}

The luciferase fragment complementation assay (LFCA) enables molecular events to be non-invasively imaged in live cells in vitro and in vivo in a comparatively cheap and safe manner. It is a development of previous enzyme complementation assays in which reporter genes are split into two, individually enzymatically inactive, fragments that are able to complement one another upon interaction. This complementation can be used to externally visualize cellular activities.

In recent years, the number of studies which have used LFCAs to probe questions relevant to cancer have increased, and this review summarizes the most significant and interesting of these. In particular, it focuses on work conducted on the epidermal growth factor, nuclear and chemokine receptor families, and intracellular signaling pathways, including IP ${ }_{3}$, CAMP, Akt, CMyc, NRF2 and Rho GTPases. LFCAs which have been developed to image DNA methylation and detect RNA transcripts are also discussed.

\section{INTRODUCTION}

Luciferase enzymes are widely used in the laboratory to meet a variety of experimental needs. They are employed in numerous assays for the visualization and quantification of cellular processes, including the analysis of cell fate, transcriptional activation, cellular signaling pathways and protein-protein interactions. As a preclinical optical imaging technique, bioluminescence can be seen to have a number of core strengths; the assays are comparatively cheap and safe and can be performed in a low or high-throughput fashion in a number of different contexts (e.g. in cell lysates, live cells and in living animals) relatively quickly and easily. However, the unrivalled advantages of bioluminescence are the sensitivity and capacity for imaging signal dynamics. Bioluminescence imaging (BLI) is capable of detecting very low intensity signals which can be quantified over several orders of magnitude. This super-sensitivity is derived from the absence of a background signal in unmodified cells and tissues, and distinguishes the technique from fluorescence imaging which typically suffers from a high background noise. Furthermore, because of the nature of the signal, bioluminescence lends itself to repeat imaging of the same subjects or samples. This can be particularly useful for imaging signal dynamics and for longitudinal studies. Repeat imaging of the same sample, rather than different cohorts, reduces data variability and can significantly reduce the number of subjects required for in vivo studies.

Luciferase enzymes

Bioluminescent light production is dependent on luciferase enzymes, which have been isolated from a variety of sources, including bacteria, insects and a number of different marine organisms [1]. Although all of the identified luciferase enzymes are oxygenases, they are non-homologous and the ability to emit light is therefore thought to have evolved more than once [2].

Luciferase enzymes from different organisms emit distinct light spectra. Although, in general, the luciferases of pelagic and deep sea organisms emit in the blue spectrum $(450-490 \mathrm{~nm})$, coastal marine organism 
Table 1: Characteristics of key enzymes used in luciferase complementation assays.

\begin{tabular}{|c|c|c|c|c|c|}
\hline & 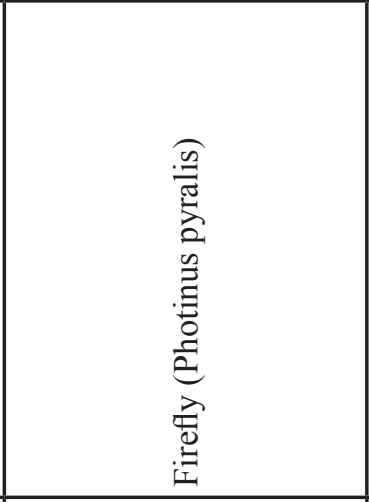 & 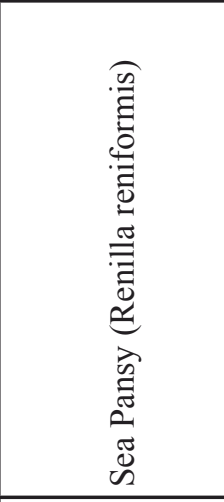 & 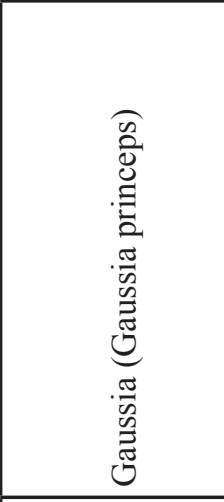 & 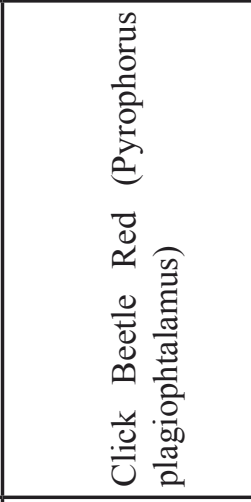 & 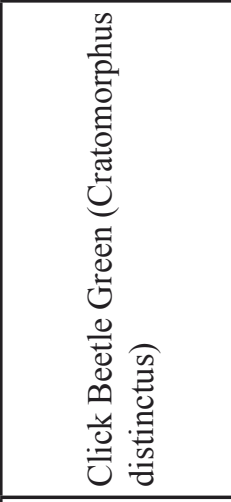 \\
\hline Amino acids & 550 & 311 & 185 & 542 & 542 \\
\hline Substrate & D-luciferin & Coelenterazine & Coelenterazine & D-luciferin & D-luciferin \\
\hline Cofactors & 02, ATP, Mg2+ & 02 & 02 & 02, ATP, Mg2+ & 02, ATP, Mg2+ \\
\hline Kinetics & Glow & Flash & Flash & Glow & Glow \\
\hline Emission & $578 \mathrm{~nm}$ & $480 \mathrm{~nm}$ & $480 \mathrm{~nm}$ & $618 \mathrm{~nm}$ & $543 \mathrm{~nm}$ \\
\hline Notable features & $\begin{array}{l}\text { red shifted to } 612 \mathrm{~nm} \text { at } \\
37^{\circ} \mathrm{C}[3]\end{array}$ & & secreted & $\mathrm{pH}$ independent & $\mathrm{pH}$ independent \\
\hline Key References & {$[12,13,26,27]$} & {$[28,79,80]$} & {$[29,60,78]$} & {$[30,31,49,58]$} & {$\left[\begin{array}{ll}30 & 31,81]\end{array}\right]$} \\
\hline
\end{tabular}

luciferases emit in the green spectrum $(490-520 \mathrm{~nm})$ and terrestrial and fresh water derived luciferases emit in the yellow-green spectrum $(550-580 \mathrm{~nm})$ [1]. The specific wavelength emitted can also be influenced by the luciferase substrate, the enzymatic environment and presence or absence of accessory proteins [1].

While luciferases have been identified in many different organisms, relatively few are commonly used in the laboratory; Table 1 lists some of the most commonly used luciferase enzymes with key references for these. The wavelength of light emitted by these enzymes ranges from blue to red, and this is an important consideration in selecting a luciferase enzyme for a specific assay. If the assay is to be used in living subjects, then a luciferase with an emission spectrum above $600 \mathrm{~nm}$ is highly desirable. This is because light absorption by tissue elements, particularly haemoglobin and water, is greatest in the blue green spectrum and is significantly less at wavelengths above $600 \mathrm{~nm}[3,4]$.

Another important distinction between the different luciferases is the substrate they use. Renilla and Gaussia luciferases use coelenterazine as a substrate while the click beetle and firefly luciferases use D-luciferin. The enzymes which use coelenterazine as a substrate exhibit "flash" kinetics; maximum light production is observed within seconds of substrate addition, after which the signal rapidly declines. This is contrary to the signal emitted from the click beetle and firefly luciferase, which is relatively stable and long lasting $[5,6]$. D-luciferin also has good bioavailability, making it especially useful for in vivo studies [6-8]. Although in vivo imaging with coelenterazine is possible, the substrate is relatively unstable in plasma and has an unfavorable biodistribution [6].

For the reasons mentioned above, namely the emission spectra and substrate availability, firefly and click-beetle red luciferases are considered the most suitable for in vivo studies.

\section{The luciferase fragment complementation assay}

The luciferase fragment complementation assay (LFCA) is a development of protein fragment complementation assays which were developed using ubiquitin, $\beta$-galactosidase and dihydrofolate reductase [912]. The basis of the assay is that the luciferase enzymes can be split into $\mathrm{N}$-terminal and C-terminal fragments (NLuc and CLuc, respectively), which in isolation are enzymatically inactive. However, when the NLuc and CLuc fragments are brought into close proximity they are able to complement one another and luciferase enzyme activity is restored. At its simplest, this can be applied to studying protein-protein interactions by fusing the NLuc and CLuc fragments to two interacting proteins of interest. When the proteins interact, the luciferase fragments are brought into close proximity and complement, enabling the interaction to be visualized by the restoration of luciferase activity (Figure 1, A). A variation of this strategy, thought 
to have much potential for imaging short-lived or lowfrequency interactions, entails covalently linking the NLuc and CLuc fragments upon protein-protein interaction using DnaE intein mediated splicing $[12,13]$. In this strategy, interaction of the proteins of interests brings together the $\mathrm{N}$ and $\mathrm{C}$ terminal fragments of DnaE, which reconstitutes the complete intein and results in the splicing together of NLuc and CLuc to produce a full length luciferase (Figure 1, B). This produces a constitutive luciferase signal which accumulates as signaling continues. An alternative approach to restoring luciferase activity by proximity is to fuse the NLuc and CLuc fragments to two probes which are able to bind to adjacent regions (Figure 1, C). This method has been employed by different groups to image changes in the nucleic acids within a cell [14-16].
LFCA strategies have also been developed to image cellular activities that involve a protein undergoing a conformational change, which encompasses many different aspects of cellular signaling. In order to achieve this, a single fusion protein in which NLuc and CLuc fragments are cloned either side of a protein/peptide sequence, or series of protein/peptide sequences, which undergo a conformational change under specific cellular conditions is engineered. A conformational change in the protein(s) alters the proximity of the luciferase fragments and subsequently the enzymatic activity (Figure 1, D). This method has been employed to image diverse cellular processes, including the activation of protein kinases, existence of specific RNA molecules and the presence of glucose or galactose [17-19].

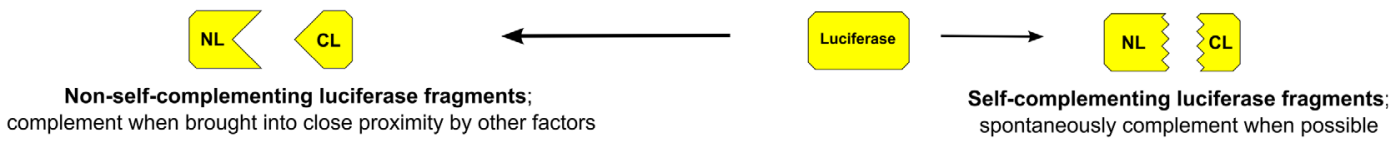

(A) Protein-protein interaction; complementation

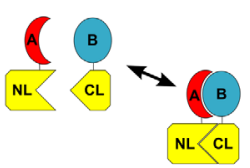

(C)
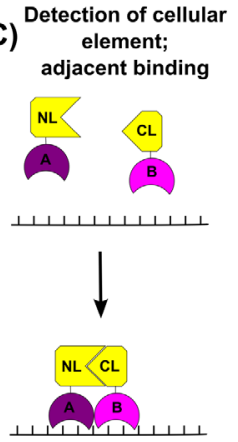
(B) Protein-protein interaction;
intein mediated splicing
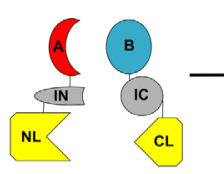

(D)

Conformational change in peptide; intramolecular complementation

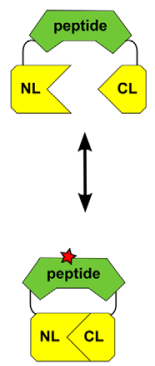

(E) Protease activation; assisted complementation

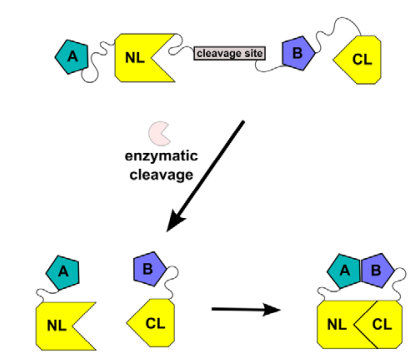

(F) Nucleo-cytoplasmic shuttling of protein A

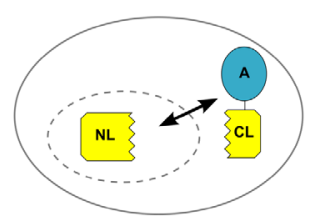

(G) Cellular delivery of macromolecule A

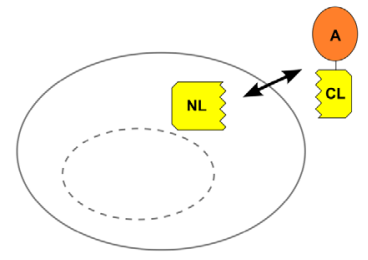

Figure 1: Summary of luciferase fragment complementation strategies. The luciferase enzyme can be split into fragments (NL and CL), which, depending upon the specific site of cleavage, will or will not spontaneously complement. Fragments which do not spontaneously complement are able to complement when brought into close proximity. Such fragments can be used to image the interaction of two proteins of interest by either a simple complementation strategy (A) or by a split-intein (NI and CI) mediated splicing strategy (B). The complementation strategy (A) is reversible and enables interaction dynamics to be visualized. In addition to imaging protein-protein interactions, luciferase fragment complementation can also be used to image the presence of a specific cellular factor by adjacent binding (C), a conformational change in a peptide/protein (D) or protein/peptide cleavage (E). In this strategy, the luciferase fragments are fused to two self associating peptides (A and B), which are only able to bind to one another once enzymatic cleavage has occurred. Luciferase fragments which spontaneously complement have also been identified and are thought to offer the potential to image protein localization (E) and cellular macromolecule delivery (F). 
A further application of LFCA is the non-invasive imaging of protease activation. This has been achieved through principally similar methods; the NLuc and CLuc fragments are fused to self-associating proteins that are prevented from interacting by a peptide hindrance. When the protease of interest is activated, it cleaves the peptide and releases the fusion proteins, thereby enabling interaction and complementation (Figure 1,E). Coppola et al. imaged caspase- 3 activation by fusing the NLuc and CLuc fragments of firefly luciferase to the interacting proteins peptide $\mathrm{A}$ and peptide $\mathrm{B}$, and separating them by a caspase 3 DEVD cleavage site [20]. Shekhawat and colleagues imaged protease activation using selfassociating coiled coils to assist luciferase fragment complementation. Activation of the protease of interest resulted in the cleavage and release of an autoinhibitory coiled-coil, which enabled luciferase fragment-fused complementary coils to associate and elicit restoration of luciferase activity [21].

Although the prevalent strategy in LFCAs is to use luciferase fragments which require assistance to complement, self-complementing luciferase fragments have been identified and are thought to offer the potential for studying protein localization and the delivery of macromolecules to cells (Figure 1, F and G [22]).

To date, by far the most commonly employed luciferase for LFCAs is that of the North American firefly, Phontinus pyralis. It is perhaps not chance that this is also one of the most widely studied luciferases. Crystal structure analysis of firefly luciferase has shown that the enzyme has a globular structure, with a large $\mathrm{N}$-terminal domain and small $\mathrm{C}$-terminal domain joined by a flexible hinge region [23-25]. The active site is believed to reside in the cleft between the two domains. The globular structure of firefly luciferase is thought to be particularly fortuitous for LFCAs. Empirical studies have determined that the best region to split firefly luciferase for complementation assays is within the flexible hinge region between the globular N- and C-terminal domains [26, 27]. However, no single preferred dissection site has been identified; the specific fusion protein context appears to have a significant impact on the restoration of enzymatic activity, and so different studies have found that subtly different NLuc and CLuc fragments produce the best signal:noise ratio. Although the knowledge base for the other commonly used luciferases is less comprehensive, Renilla, Gaussia and click beetle luciferases have all been used to image molecular events using LFCA [28-30]. By using two luciferases with different emission spectra, simultaneous imaging of more than one molecular event within a single cell has also been achieved by different groups [30-32].

\section{Advantages of the luciferase fragment complementation assay}

As previously discussed, luciferase imaging is a highly sensitive, safe and cheap technique which can be performed numerous times on the same sample in a relatively high-throughput fashion in vitro and in vivo. In addition to these practical advantages, the LFCA has distinct benefits from the view of experimental design. These benefits principally revolve around the fact that the luciferase fragment fusion proteins are primed and ready to respond to stimuli rapidly, and are able to freely, and repeatedly, associate/dissociate as required.

In cell free systems and cellular lysates, it has been demonstrated that a plateau in luciferase fragment complementation is generally achieved within 1 or 2 minutes of ligand addition [19, 26, 33], although some studies have indicated that a plateau is reached in as little as 5 seconds [34]. From this, it has been inferred that the process of luciferase fragment complementation does not significantly impact the timeframe with which cellular processes can by visualized, i.e. the delays observed are a product of the cellular process, not the act of enzyme restoration. This potential for near real-time visualization of cellular processes is particularly advantageous given that the sample can be repeatedly imaged, thereby allowing the dynamics of a cellular response to be recorded over seconds, minutes or hours.

In addition to being able to detect the kinetics of stimulus response, LFCAs can also be used to visualize the termination of signaling because the complementation observed between luciferase fragments is reversible $[29,30,35]$. This is in contrast to fluorescent protein complementation assays, which have been shown to be irreversible due to the folding and maturation of the fluorescent $\beta$-barrel $[36,37]$. Depending on the system being studied, inhibitor induced alterations in complementation between luciferase fragments has been observed within seconds or minutes, again suggesting that the timeframe of luciferase fragment dissociation does not significantly impact the visualization of cellular responses.

\section{Preclinical cancer studies using the LFCA}

\section{Cellular receptors}

One of the principal areas to which LFCA has been applied is the modulation of cellular receptors. This has been achieved through a number of different strategies: receptor hetero- and homo- dimerization, receptor-effector interaction and ligand induced alterations in protein conformation. The activity of a number of different receptors has been investigated using LFCA. However, 
in this review, we will focus on the work conducted on 3 receptor families which are particularly significant in oncology and have attracted a sizable body of work.

\section{LFCA imaging of the epidermal growth factor receptor family}

The epidermal growth factor receptor family, which consists of EGFR/Her1, Her2, Her3 and Her4, has been implicated in a variety of different cancer types. The receptors are tyrosine kinases which homoor heterodimerize upon ligand stimulation. Receptor dimerization leads to activation of the intracellular kinase domain, autophosphorylation, the recruitment of adaptor proteins and the subsequent activation of intracellular signaling pathways for signal propagation. EGFR and Her2 are probably the most widely studied family members, not least because they are also most heavily implicated in tumorogenesis. EGFR is overexpressed in more than $60 \%$ of non-small cell lung carcinomas (NSCLC) and activating mutations have been detected in approximately $20 \%$ of all NSCLC patients $[38,39]$. Her2 is amplified or overexpressed in $20-30 \%$ of breast cancer patients, and is associated with a more aggressive disease and worse prognosis [40]. The involvement of the EGFR family in numerous different cancers has made them the target therapeutic intervention, and as such methods to image the activity of the receptors have been investigated by several different groups.

By producing EGFR-NLuc and EGFR-CLuc fusion protein constructs, Yang and colleagues have noninvasively imaged the conformational changes that occur in EGFR after ligand stimulation [41]. Contrary to their initial expectations that EGF stimulation would increase receptor dimerization, and therefore luciferase activity, the group found that the addition of EGF produced a rapid decrease in luciferase activity followed by a recovery which lasts approximately 20 minutes. Using kinase dead EGFR mutants and the EGFR tyrosine kinase inhibitor erlotinib, the group were able to show that the decrease in luciferase activity was dependent on receptor kinase activity, but was not thought to be related to the process of tyrosine phosphorylation itself because of the timeframe of the observed changes. As such, the initial decrease in luciferase activity was attributed to conformational changes in the receptor which occur after tyrosine phosphorylation. These conformational changes have previously been demonstrated by crystallographic studies, but not in cellular systems prior to their work. Using the MAPK inhibitor U0126 and by creating EGFR-Thr ${ }^{669}$ mutants, it was shown that the subsequent recovery of luciferase activity was dependent on EGFR stimulated activation of the MAPK pathway.

As per the original hypothesis, the group were able to image EGFR dimerization by producing C-terminally truncated EGFR fusion proteins. This was validated by comparing the timeframe of dimerization, as observed by LFCA, with the timeframe of ${ }^{125} \mathrm{I}-\mathrm{EGF}$ binding. Using these fusion proteins the group were able to show the effect of novel small molecule inhibitors on receptor dimerization [42].
A
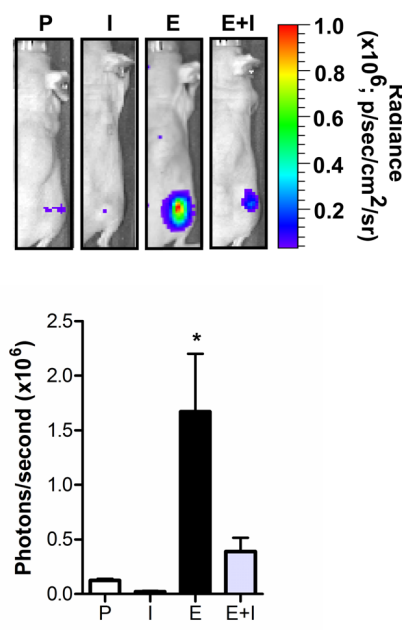

B
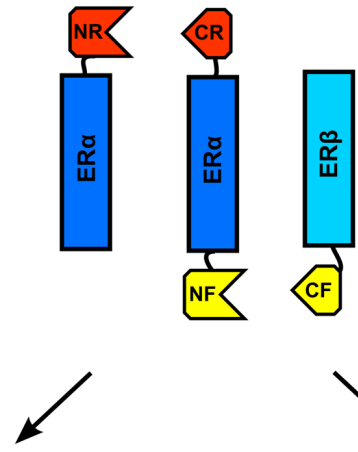

Renilla luciferase ERa homodimerization

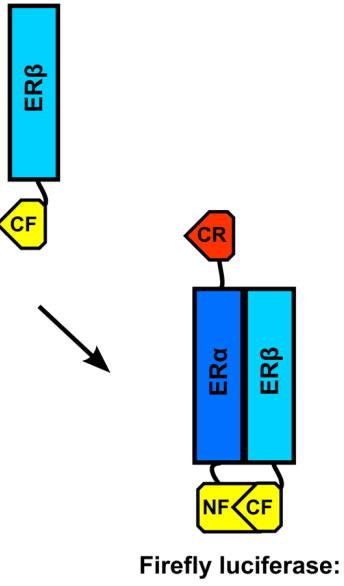

ER $\alpha / E R \beta$ heterodimerization

Figure 2: Imaging estrogen receptor biology. (A) By imaging the interaction of estrogen receptor $\alpha(E R \alpha)$ with the coactivator AIB1, activation of ER $\alpha$ by estrogen (E) and subsequent inhibition by the anti-estrogen ICI (I) can be non-invasively imaged in vivo. $\mathrm{P}=$ placebo. (B) Strategy to simultaneously image ER $\alpha / \mathrm{ER} \alpha$ and $\mathrm{ER} \alpha / \mathrm{ER} \beta$ dimerization using Renilla $(\mathrm{NR} / \mathrm{CR})$ and firefly $(\mathrm{NF} / \mathrm{CF})$ luciferases, respectively. Figures have been adapted from [52] and [32], respectively. 
Using NLuc and CLuc labeled EGFR and Her2 fusion proteins, the same group went on to examine the dynamics of EGFR/Her2 heterodimer formation following EGF stimulation [43]. Her2 is the preferred dimerization partner of EGFR, and their dimerization is thought to have important consequences for disease. The group found that the same characteristic profile of luciferase activity was observed during hetero- and homodimer formation. Using different combinations of wild-type and kinase-dead EGFR and Her2 fusions proteins, the specific mechanics of asymmetrical kinase dimer formation were explored. The group found that the binding of EGF to EGFR stimulates EGFR to undertake a "receiver" kinase position, resulting in the EGFR kinase domain being activated prior to the Her2 kinase domain - a novel finding which had not previously been appreciated.

In addition to demonstrating the mechanics of EGFR signaling, LFCAs have also been used to the image activation and inhibition of growth factor receptor signaling. Chuan-Yuan Li's laboratory has imaged the activation of EGFR and Her2 by monitoring the association of the receptor with the downstream adaptor protein She [44-46]. Using this strategy, the group have imaged the in vivo activation of EGFR and Her2 by ionizing radiation and the activation of EGFR by hyperthermia.

Using a "intramolecular complementation" strategy, Amjad Khan and colleagues have imaged EGFR activity by producing a single fusion protein which consists of the tyrosine phosphorylation site of EPS15 and the SH2 domain of p52 cloned between the $\mathrm{N}$ and C terminal fragments of firefly luciferase [47]. In the absence of EGFR activity, the NLuc and CLuc fragments complement, producing a high level of luciferase activity. However, activation of EGFR results in phosphorylation of the EPS15 domain, which subsequently interacts with the SH2 domain, and alters the conformation of the fusion protein to prevent complementation between the luciferase fragments. The specificity of the changes in luciferase activity for EPS15 phosphorylation and EGFR activation were demonstrated using an EPS15 mutant and by siRNA mediated knockdown of EGFR. A particular strength of the strategy used by Amjad Khan et al. is that activation and inhibition of EGFR can be imaged by monitoring decreases or increases in luciferase activity. Furthermore, the system also enables visualization of EGFR activity without directly modifying the receptor itself, which could lead to unintended alterations in its biological activity. However, the reporter did demonstrate some unfortunate signal attenuation over time, which limits it potential for time-course studies.

\section{Nuclear receptor imaging}

Nuclear receptors, which have been implicated in a number of different diseases, including cancer, comprise a large family of ligand activated transcription factors which stimulate gene expression by binding to coactivator proteins. LFCA studies of nuclear receptors have principally involved the estrogen and androgen receptors, which are primarily implicated in breast and prostate cancer, respectively.

The action of the androgen receptor (AR) has been imaged using a number of different strategies by Yoshio Umezawa's laboratory. Upon ligand binding, the AR undergoes a conformational change which results in the ligand binding domain (LBD) of the receptor interacting with the receptor $\mathrm{N}$-terminus. Using a firefly luciferase intramolecular folding sensor, the group have shown that the kinetics of this conformational change differs in response to different AR ligands [48].
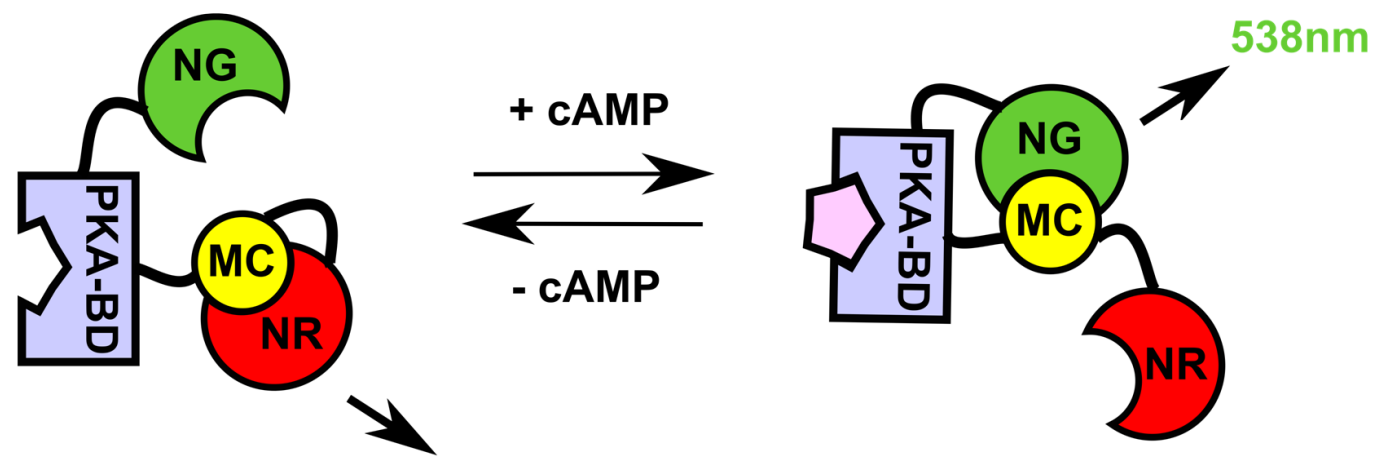

$613 \mathrm{~nm}$

Figure 3: Dual wavelength ratiometric sensor for imaging cAMP levels. Takeuchi and colleagues have successfully imaged cAMP levels using an engineered $\mathrm{C}$ terminal click beetle (CB) luciferase fragment (MC) which can complement with the $\mathrm{N}$ terminal fragment of $\mathrm{CB}$ red $(\mathrm{NR})$ and green $(\mathrm{NG})$ luciferases to emit red or green light, respectively. In the presence of cAMP, the intramolecular fusion protein undergoes a conformational change due to the inclusion of the cAMP binding domain of PKA (PKA-BD). Figure has been adapted from [63]. 
Using a similar click beetle red intramolecular fusion protein, the same group imaged the ligand induced association of the AR-LBD with the conserved LXXLL motif of nuclear receptor coactivators [49]. This interaction is required for transcriptional activation by the AR, and can therefore be considered a measure of the receptors genomic activity.

As an alternative method to measure AR genomic activity, Umezawa's group have also produced a pair of split Renilla luciferase fusion proteins to quantify the translocation of the AR from the cytoplasm to the nucleus following ligand binding [50]. Fusion proteins were produced in which the $\mathrm{N}$ terminus of Renilla luciferase and DnaE were fused to a nuclear localization sequence, and the $\mathrm{C}$ terminus of Renilla luciferase and DnaE were fused to the AR. Upon nuclear translocation of the AR construct, the $\mathrm{N}$ and $\mathrm{C}$ terminal fragments of the DnaE fragments complement and splice together the two luciferase fragments, thereby restoring the enzymatic activity. Because the restored luciferase activity depends upon a slicing event, the signal is irreversible and is cumulative. It is argued that this accumulation makes the assay more sensitive and therefore more suitable for highthroughput screening and in vivo imaging.

In addition to its genomic actions, the AR is also able to signal in a non-genomic fashion. Umezawa's group have investigated the ligand induced non-genomic actions of AR by imaging the association of the AR with Src [51]. Interestingly, they find that some AR ligands exhibit different specificities for stimulating the genomic and non-genomic actions of the receptor, which could have important implications in the design of novel AR therapeutic agents.

Similar to the central role which the AR plays in prostate cancer, the estrogen receptor (ER) is seen as a key player in breast cancer. As a novel means of imaging the genomic actions of ER alpha $(E R \alpha)$, we have produced firefly luciferase fusion proteins for $\operatorname{ER} \alpha$ and the nuclear receptor coactivator AIB1. AIB1 is thought to be fundamental to estrogen signaling in breast cancer, and the ER $\alpha$-coactivator/AIB1 interaction is a novel target for drug development. Using ER $\alpha$ and AIB1 fusion proteins, we have demonstrated an estrogen dependent increase in ER $\alpha$-AIB1 interaction which is modulated by anti-estrogen treatment. These alterations in luciferase activity can be observed within minutes of ligand addition and the specificity of the complementation to ER $\alpha$-AIB1 interaction was confirmed using mutant ER $\alpha$ fusion proteins. The constructs were subsequently applied to imaging the action of ER agonists and antagonists in living subjects (Figure 2A; [52]), and are thought to offer much potential for screening novel breast cancer therapeutics, particularly those that target ER $\alpha$-coactivator/AIB 1 interaction.

The laboratory of Samjiv Gambhir has also investigated ER activity using the spit luciferase technique. Using an intramolecular folding sensor, in which ER $\alpha$ is flanked by the $\mathrm{N}$ and $\mathrm{C}$ terminal fragments of Renilla luciferase, ligand induced conformational changes in the receptor have been imaged [53]. By removing the $\mathrm{C}$
A

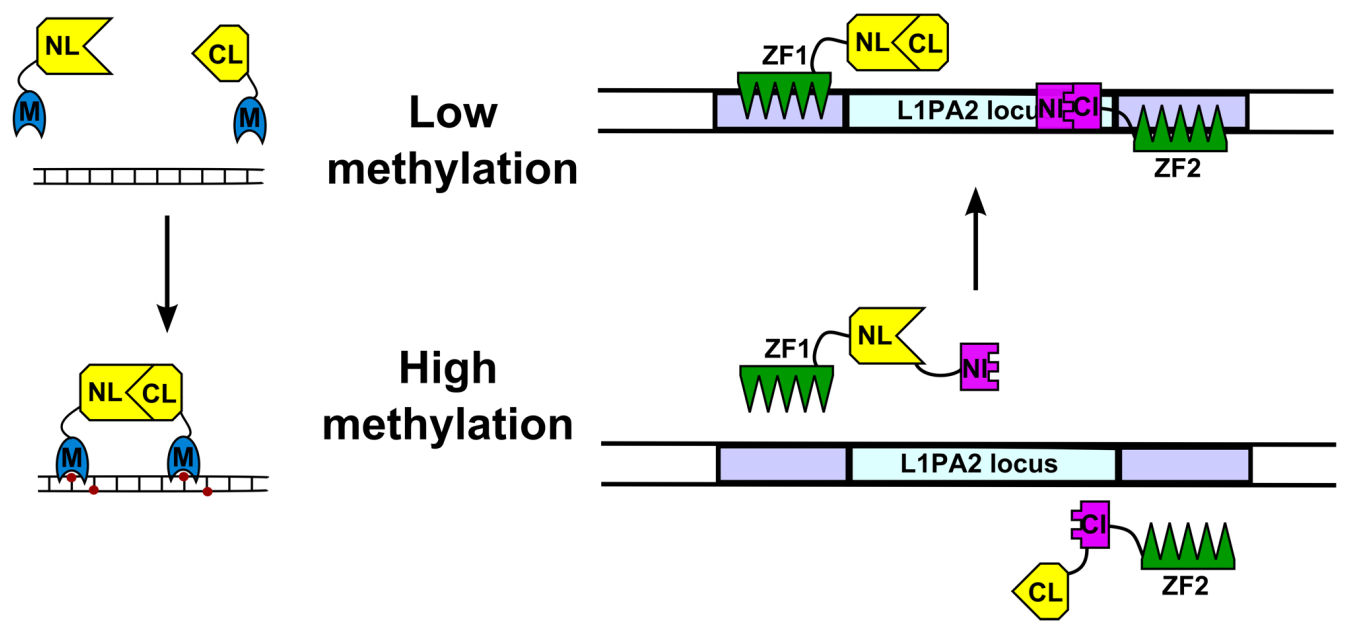

Figure 4: Imaging of DNA methylation. (A) Badran and colleagues have imaged global DNA methylation using the CpG island binding protein MBD1 (M). In high methylation conditions, luciferase fragment fused MBD1 proteins bind to adjacent CpG islands (red dots) and complementation between luciferase fragments can occur. (B) Using artificially engineered zinc finger proteins (ZF) which recognize specific DNA sequences, Huang and colleagues have imaged methylation at the L1PA2 locus. In the absence of methylation, the DNA is more accessible and the ZF proteins can bind to the DNA, leading to complementation between the intein fragments NI and CI, and splicing together of the two luciferase fragments. Figures adapted from [14] and [15], respectively. 
terminal $\mathrm{F}$ domain from the ER $\alpha$ fragment, they found that ligands with different pharmacologies were clearly distinguishable by the intensity of the luciferase signal produced. In the same study, the group also identified and characterized an interesting ER $\alpha$ mutation (G521T), which effectively abolished the binding of estrogen to ER $\alpha$, but had minimal impact on the binding of other ligands [53, 54]. Using this mutant, they were able to image ligand induced modulation of the chimeric protein in vivo, without endogenous estrogen competing for binding with the administered compounds. It is argued that this mutant could be of significant application for the in vivo characterization of estrogen receptor modulators.

The Gambhir group have also investigated ER $\alpha$ and ER $\beta$ hetero- and homodimerization using LFCA [32]. ER $\beta$ is a nuclear receptor which shares significant sequence homology with $\mathrm{ER} \alpha$, but exhibits distinct ligand binding affinities and signaling outcomes. ER $\beta$ is not believed to be implicated in the development or progression of cancer and there is significant interest in developing and understanding the actions of ER $\alpha$ and ER $\beta$ specific ligands. Using LFCA, the Gambhir group showed that ER $\alpha$-specific, ER $\beta$-specific and non-specific ER ligands produce distinct patterns of $\mathrm{ER} \alpha / \mathrm{ER} \beta$ homo- and heterodimerization. Using G521T mutant receptors, which are unable to bind estrogen, they were also able to show that receptor dimers can form when only one receptor is occupied by ligand.

By producing an $\mathrm{ER} \alpha$ fusion protein which was $\mathrm{N}$ terminally tagged with the NLuc of firefly luciferase and $\mathrm{C}$ terminally tagged with the CLuc of Renilla luciferase, the group was also able to simultaneously image ER $\alpha$ / $\mathrm{ER} \alpha$ homodimerization and $\mathrm{ER} \alpha / \mathrm{ER} \beta$ heterodimerization in response to different ligands (Figure 2B). Cotransfection of this fusion protein with Renilla-NLuc-ER $\alpha$ and ER $\beta$-firefly-CLuc fusion proteins allowed ER $\alpha / \mathrm{ER} \alpha$ homodimerization and $\mathrm{ER} \alpha / \mathrm{ER} \beta$ heterodimerization to be simultaneously measured by quantifying Renilla and firefly luciferase activities, respectively.

\section{Chemokine receptor imaging}

Chemokine receptors form a large family of 7-transmembrane G-protein coupled receptors (GPCR) which are activated in response to cytokine binding to mediate cell migration. Chemokine receptors have been implicated in a number of different diseases, including HIV, inflammatory diseases and a number of different human cancers.
A
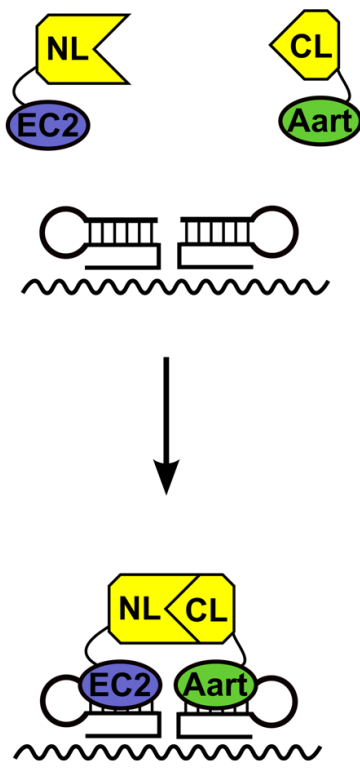

B

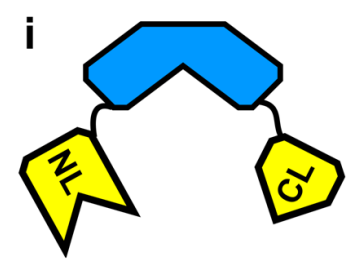

ii

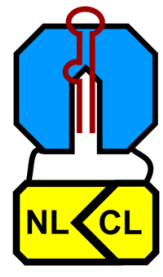

iii
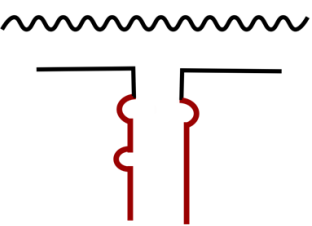

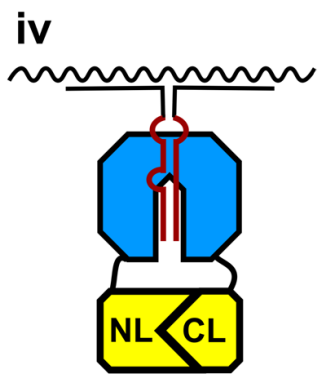

Figure 5: Imaging of RNA transcripts. (A) Furman and colleagues have imaged the presence of specific RNA transcripts using the double stranded DNA binding proteins EC2 and Aart. Single stranded DNA probes, attached to double stranded DNA recognition sequences for EC2 and Aart, are engineered for the RNA of interest. These serve as a platform for luciferase fragment complementation. An alternative method for imaging the presence of specific RNAs has been developed by Kobatake's group. The group use the HIV-1 Rev-peptide and BIV Tat-peptide (blue polygon) which undergo a conformational change upon binding to the RNAs (depicted in red) RRE-RNA and TAR-RNA, respectively (B.i and ii). In order to detect a specific RNA of choice, the group produced split RNA probes to anneal to the RNA of interest and reform the RRE-RNA or TAR-RNA (B.iii). Once reformed, the RRE-RNA or TAR-RNA is detected by the HIV-1 Rev-peptide or BIV Tat-peptide and a change in luciferase activity is observed (B.iv). Figures adapted from [16] and [18], respectively. 
Kathryn and Gary Luker have imaged different aspects of CXCR4 and CXCR7 biology using a variety of luciferase fragment complementation strategies. By producing NLuc and CLuc CXCR4 or CXCR7 fusion proteins they have imaged ligand induced conformational changes in CXCR4 and CXCR7 receptor homodimers [55]. Using this approach, they have shown that the timeframes of CXCR4 and CXCR7 signaling are different. However, because both receptors form dimers in the unliganded state, the changes in complementation observed using this strategy tended to be quite modest, which could limit application of this assay. As an alternative strategy to image CXCR4 and CXCR7 activation, the group produced luciferase fragment fusion protein to visualize the association of the receptors with the adapter protein $\beta$-arrestin. Employing this strategy enabled them to observe much greater increases in complementation with ligand binding and also to confirm the different timecourses of CXCR4 and CXCR7 signaling; in response to the ligand CXCL12, CXCR4- $\beta$-arrestin interaction peaks within 10 minutes and swiftly declines over the next 45 minutes whereas CXCR7- $\beta$-arrestin interaction continues to increase for up to 4 hours [56, 57]. Using the CXCR7$\beta$-arrestin constructs, the group were also able to show that two newly identified CXCR7 antagonists, which had previously been characterized in cell free ligand binding assays, actually behave as agonists in their cellular system [57].

More recently, the group have also produced CXCR4/ $\beta$-arrestin click beetle red split luciferase constructs [58]. The emission spectra from this luciferase should provide enhanced capability for in vivo imaging, and the group has used these constructs to demonstrate the advantages of combining cisplatin therapy with the CXCR4 inhibitor AMD3100 in mouse models of ovarian cancer.

In an innovative application of the split luciferase assay, the Luker group have also imaged the binding of the peptide ligand CXCL12 to the receptors CXCR4 and CXCR7 by producing ligand- and receptor-Gaussia luciferase fragment fusion proteins $[59,60]$. Using this system, they were able to directly visualize the blockade of ligand binding by inhibitor treatment in vitro and in vivo, and show that inhibition of CXCL12-CXCR4 binding resulted in reduced tumor formation.

By means of another Gaussia luciferase complementation assay, the group has also investigated the dimerization of CXCL12, a ligand of both CXCR4 and CXCR7 [61]. By producing cells lines which express NLuc- or CLuc-fused CXCL12 the group show that CXCL12 is secreted as both a monomer and dimer, and that CXCL12 dimers can also form in the extracellular matrix. Using a range of split luciferase and non-luciferase based techniques, the group show that CXCL12 monomers and dimers activate different signaling pathways through CXCR4, and that CXCR7 preferentially binds to CXCL12 monomers rather than dimers. This could have important implications in the development of novel CXCR4 or CXCR7 antagonists.

\section{LFCA imaging of intracellular signaling pathways}

Intracellular signaling pathways are effectors of a range of different oncogenic or tumor suppressing signals, and can be used as a means to gauge the efficacy of treatments which aim to preclude tumor formation or progression. As such, methods to image these pathways are highly desirable, and LFCAs have been produced for a number of different intracellular signaling molecules at different stages of signal transduction.

\section{Secondary messenger imaging}

The secondary messengers $\mathrm{IP}_{3}$ and cAMP are produced in response to G-protein coupled receptor (GPCR) activation, and can serve as useful biomarkers for the activation or inhibition of a number of different receptors. GPCRs have been implicated in many different human diseases, including cancer, and are the targets of many established and novel anti-cancer therapies. Both $\mathrm{IP}_{3}$ and cAMP have been imaged by LFCA.

Using the core $\mathrm{IP}_{3}$-binding domain of the mouse receptor $\mathrm{IP}_{3} \mathrm{R} 1$ flanked by $\mathrm{N}$ and $\mathrm{C}$ terminal fragments of firefly luciferase, Ataei et al. have been able to image very rapid, transient fluxes in $\mathrm{IP}_{3}$ levels [62]. In cell lysates, the group observed a plateau in the luciferase signal, corresponding to a change in the conformation of the $\mathrm{IP}_{3}-$ binding domain, 5 seconds after the addition of $\mathrm{IP}_{3}$. In whole cells, changes in cellular $\mathrm{IP}_{3}$ levels after stimulation with the peptide Bradykinin were visualized, with a peak signal 30 seconds after addition of the peptide.

In order to image alterations in cellular cAMP levels, Takeuchi et al. produced a dual wavelength ratiometric intramolecular split luciferase sensor (Figure 3; [63]). The sensor applied a previously engineered $\mathrm{C}$ terminal click beetle luciferase fragment (McLuc1) which can complement with the $\mathrm{N}$ terminal luciferase fragments of click beetle luciferase red (NLuc-CBR) and green (NLuc$\mathrm{CBG}$ ) to emit light at $630 \mathrm{~nm}$ and $525 \mathrm{~nm}$, respectively [31]. In this study, a single fusion protein comprising the cAMP binding domain of PKA (PKA-BD) flanked by NLuc-CBG on the amino terminal and McLuc1 and NLucCBR on the carboxy terminal was produced and expressed in HEK293 cells. In the absence of cAMP, the McLuc1 fragment complemented with NLuc-CBR, emitting light at $613 \mathrm{~nm}$, but in the presence of cAMP, an alteration in the PKA-BD conformation reduced McLuc1-NLuc-CBR complementation and promoted McLuc1-NLuc-CBG complementation, increasing emission at $538 \mathrm{~nm}$. By comparing the ratio of light emitted at $525 \mathrm{~nm}$ and $630 \mathrm{~nm}$, the group was able to detect dose dependent increases in 
cAMP concentration [63]. To ensure that this ratio was not impacted by fluctuations in luciferin and ATP (while red and green filter images are sequentially captured) the group performed luciferin and ATP titrations and showed that although the individual luciferase activities were affected, the ratio of light emitted at $525 \mathrm{~nm}$ and $630 \mathrm{~nm}$ was largely unaffected. Using the ratiometric sensor, alterations in cellular cAMP concentrations following ISO and forskolin addition were imaged using a bioluminescence microscope with red and green long-pass filters. A modest increase in the 520/630 ratio could also be imaged in vivo 10 minutes after the administration of ISO. However, differential attenuation of the red and green signal could have seriously impacted the ability to observe any changes in this context, particularly given that the positive signal was in the green filter, which would have suffered greater signal attenuation than the red filter signal.

\section{Kinase imaging}

Serine/threonine kinases play important roles in the regulation of numerous different cellular pathways, including those relevant to cancer, and have been imaged by LFCA in a number of different ways.

The activity of the key signaling molecule Akt, a serine/threonine kinases which is involved in cell proliferation and survival, has been probed in a number of different LFCA studies. Using an intramolecular folding sensor consisting of an Akt kinase substrate peptide and the phosphopeptide-binding FHA2 domain from Rad53p flanked by NLuc and CLuc fragments, Zhang and colleagues have imaged modulation of Akt activity in cells and living animals [17]. In the presence of EGF or serum, which stimulate Akt activity, a decrease in luciferase activity was observed. Conversely, an increase in luciferase activity was observed with Akt inhibitors. The specificity of the observed changes for Akt was demonstrated using mutant constructs and by immunoprecipitation of the reporter, which showed that the phosphorylation status of the reporter correlated with Akt activity. Western blotting was also used to demonstrate that the luciferase signal observed correlated with the endogenous Akt phosphorylation status. Using this LFCA, the group was able to show that the Akt inhibitors API2 and perifosine exhibit individual pharmacodynamics in vitro and in vivo.

In a very similar study, Chan and colleagues produced an Akt kinase motif-FHA2 intramolecular fusion protein, and observed similar decreased complementation with Akt activation and increased complementation with Akt inhibition [64]. Although Chan's study used slightly different drugs and looked at reporter complementation in hours rather than minutes, the results of this study are largely similar and in agreement with the study of Zhang et al. However, an interesting addition to this study is that they use the reporter to screen 1280 compounds from the
LOPAC library and identify a novel Akt inhibitor.

The phosphopeptide-binding FHA2 domain of Rad53p has also been employed to image the activity of the serine/threonine kinases GSK $3 \beta$ and CK $1 \alpha$, which have both been reported to be dysregulated in a number of different human diseases, including cancer [65]. A single fusion protein consisting of the FHA2 domain and a 20 amino acid peptide sequence derived from $\beta$-catenin, which includes substrate sequences for both kinases, flanked by NLuc and CLuc sequences was produced. In common with the previous FHA2 studies, the group found that kinase inhibition led to a dose and time dependent increase in luciferase complementation, which was shown to correlate with $\beta$-catenin phosphorylation by western blotting. Mutant reporter constructs were used to demonstrate the specificity of the signal increase for either GSK $3 \beta$ or CK $1 \alpha$ phosphorylation and in vivo imaging demonstrated the dynamics of $\mathrm{LiCl}$ inhibition of GSK3 $\beta$.

\section{Transcription factor imaging}

Although the dominant method for luciferase imaging of transcription factor activation is to produce a response element-luciferase reporter construct, in which the transcription of luciferase is driven by a specific promoter element, LFCA can also be applied to imaging transcription factor activation and can be seen to have some specific advantages. Unlike transcriptional reporter assays, LFCA can image the transcription factor directly, and so the read-out is not limited to a single/ set of promoter elements. Furthermore, because the assay is primed and reversible in nature, the kinetics of activation can be visualized without relying upon cycles of transcription to produce a signal and protein turn-over to abolish a signal.

c-Myc is a transcription factor which is dysregulated in many different cancers. The frequency with which c-Myc is dysregulated in cancer suggests that it is a key regulator and, as such, has significant therapeutic potential. Fan-Minogue and colleagues have non-invasively imaged the dynamics of c-Myc by producing luciferase fragment fusion proteins to image the phosphorylation dependent association of c-Myc with GSK3 $\beta$ [66]. By transfecting these constructs into different cell lines, the group was able to clearly differentiate the different levels of endogenous c-Myc phosphorylation in the different cell lines, which were confirmed by western blotting. The group went on to show that the impact of MAPK inhibitors on c-Myc activation could be imaged using LFCA in vitro and in vivo, even though no alterations in tumor size could be observed.

Nrf2 is a transcription factor which is activated in response to cellular stress, particularly redox stress, to stimulate cell protective pathways. In the absence of stress signaling, inactive Nrf2 resides in the cytoplasm in association with its repressor Keap1, but upon 
stimulation Nrf2 is phosphorylated, dissociates from Keap1 and translocates to the nucleus. In the nucleus, Nrf2 associates with nuclear factors such as MafK and RunX2 to stimulate transcription from antioxidant response elements. Traditionally, Nrf2 has been considered a tumor suppressor, and Nrf2 activators have been developed in order to stimulate Nrf2 mediated cell protective pathways. However, new evidence suggests that $\mathrm{Nrf} 2$ is overactive in some cancers and can be associated with chemoresistance in these cancers, indicating that Nrf2 inhibitors could be of therapeutic use. Recently, LFCAs for Nrf2 have been developed by two independent groups to non-invasively image Nrf2 activity. Xie et al. have produced luciferase fragment fusion proteins to image the association of nuclear Nrf2 with either MafK or RunX2 [67] while Ramkumar et al. have produced a LFCA to image the dissociation of Nrf2 from Keap1 [68]. Both of these assays were developed with the specific aim of producing a robust high-throughput technique for identifying Nrf2 modulators. Although different Nrf2 activators were used in each study and the outputs were opposing (i.e. imaging association versus dissociation), the results from these studies were in accordance. While both studies were very much directed at developing a high-throughput platform, the study by Ramkumar et al. did also demonstrate the transition into in vivo studies using the Nrf2 activator PTS.

\section{Rho GTPase imaging}

Rho GTPases are a subfamily of the Ras superfamily, which integrate signals from a number of different extracellular stimuli to influence cellular proliferation, gene expression and apoptosis. Rho GTPases have been shown to be dysregulated in a number of different diseases. In cancer, Rho GTPases are thought to play a role in the formation and progression of tumors, and as such, they are considered potentially valuable therapeutic targets. Leng et al. have imaged the activity of the three most widely studied Rho GTPases, CDC42, Rac1 and RhoA, through the association of the GTPases with their specific effectors: WASP, PAK and PKN, respectively [69]. The specificity of the luciferase activity for Rho GTPase-effector interaction was demonstrated by co-transfection of mismatched Rho GTPase/effector pairs and by producing mutant constructs with impaired GTPase activity or with a reduced G-protein affinity. The group was able to clearly visualize the complementation for each Rho GTPase-effector pair in cells and animals and noted that compared to similar FRET experiments, the dynamic range with LFCA was greater, suggesting that it will offer enhanced differentiation of signal modulation. The group also demonstrated that the magnitude and kinetics of activation was different for different Rho GTPase/ligand combinations.

\section{Imaging alterations in nucleic acid status}

Nucleic acids are fundamental to cellular behavior, and alterations in nucleic acid regulation are frequently observed in human cancers. The consequences of these changes are probably most often appreciated at the level of protein expression. However, as our appreciation of epigenetics develops, so does our interest in determining the specific causes of changes in gene expression.

DNA methylation has emerged as one of the principal epigenetic mechanisms through which gene expression is dysregulated in cancer, and there is currently much interest in the development of novel epigenetic drugs to alter DNA methylation status. In order to image global DNA methylation, Badran and colleagues have developed a firefly luciferase based LFCA using the methyl CpG binding domain 1 (MBD1), which has a 110 fold preference for methylated (versus unmethylated) DNA [14]. The group produced MBD1-NLuc and MBD1-CLuc fusion proteins and demonstrate that increased luciferase activity is observed in the presence of methylated DNA, when the MBD1 fusion proteins bind to adjacent methylated $\mathrm{CpG}$ dinucleotides and the luciferase fragments complement (Figure 4A). The group show a dose dependent decrease in luciferase activity when purified MBD1 fusion proteins are incubated with DNA purified from cells treated with increasing concentrations of the demethylating agent decitabine. The decrease in methylation in the decitabine treated DNA was verified by methylation sensitive endonuclease digestion.

In order to assess the methylation status of specific promoters, Huang et al. used engineered polydactyl zinc finger (PZF) proteins to bind to sequences either side of the locus of interest [15]. The principle of this strategy is that methylation reduces the accessibility to the DNA, and so reduces PZF protein binding, which can consequently be used as an indirect marker of methylation. The group apply their technique to imaging the L1PA2 locus which is reportedly demethylated following azacytidine and decitabine treatment, leading to increased expression of the cMet oncogene. Two fusion proteins, each consisting of five PZF domains, a VMA intein fragment and a firefly luciferase fragment were engineered and expressed in Hela cells. Upon adjacent sequence recognition (in low methylation conditions), the intein fragments complement and splice the luciferase fragments together, resulting in restored enzymatic activity (Figure 4B). By transfecting plasmids which contain the L1PA2 target sequences into fusion protein expressing Hela cells (where the endogenous L1PA2 locus is predominantly methylated), the group were able to show an increase in luciferase activity which correlates with the presence of the unmethylated target sequence. However, sizeable increases, attributed to background intein splicing, were also observed in empty vector transfections. The group went on to demonstrate a dose dependent increase in 
luciferase activity in cells treated with the demethylating agents decitabine and azacitidine.

RNAs, both coding and non-coding, are a major determinant of protein expression and cellular behavior, and consequently an ability to non-invasively image cellular RNAs could have a significant impact in cancer studies. Although to date limited to cell free systems, different groups have developed LFCAs to image RNAs, which could potentially be applied to the analysis of purified RNA in the future $[16,18,70]$. Perhaps the most promising of these is that of Furman and colleagues, who use DNA probes to detect specific RNA transcripts [16]. The principle of this strategy is to attach double stranded DNA recognition sequences for the high affinity zinc finger proteins EC2 and Aart to single stranded DNA probes that are complementary to adjacent regions of an RNA of interest. The double stranded EC2 and Aart binding sequences are subsequently used as a platform for luciferase fragment-fused EC2 and Aart proteins to bind, which bring the luciferase fragments into close proximity and allow the enzymatic activity to be restored (Figure $5 \mathrm{~A})$. Using this strategy, the group has been able to detect VEGF, HER2 and hDM2 RNA transcripts.

Eiry Kobatake's group has also attempted to image the presence of specific RNA molecules using the HIV1 Rev-peptide and BIV Tat-peptide, which bind to the Rev-aptamers RRE-RNA and TAR-RNA, respectively $[18,70]$. Binding of the peptides to their respective RNAs produces a conformational change which they have exploited to alter the proximity of flanking luciferase fragments, altering the complementation status and the subsequent luciferase activity. In cell free systems, the group has successfully produced HIV-1 Rev-peptide and BIV Tat-peptide luciferase fragment fusion proteins which elicit a specific change in luciferase activity upon exposure to their respective RNAs (Figure 5B.i and ii). The group have attempted to extend this technology to detecting a specific RNA of choice by splitting the Rev-aptamers, RRE-RNA or TAR-RNA, and fusing each half to RNA sequences which are complementary for adjacent regions of a specific RNA of choice. In the presence of the RNA, the split RNA- Rev-aptamer/RRERNA/TAR-RNA oligonucleotides anneal to the RNA of interest and the complete Rev-aptamer/RRE-RNA/TARRNA target reforms. In the presence of the reformed target, the HIV-1 Rev-peptide/BIV Tat-peptide-split luciferase probe undergoes a conformational change, which alters the complementation between the associated luciferase fragments (Figure 5B.iii and iv). This is quite a complicated system, which has principally worked in cell free systems, but the limits of detection are currently insufficient to be transferred into cellular systems.

In addition to being a cause of cancer, nucleic acids also provide an effective means of restricting cancer growth. Radiotherapy and some chemotherapies aim to induce DNA damage in order to stimulate cell death.
Assess the efficacy of different treatment regimes, $\mathrm{Li}$ and colleagues have developed a LFCA to non-invasively image the formation of DNA double strand breaks (DSB) in vitro and in vivo [71]. The group use luciferase fragment fusion proteins to image the association of histone H2AX, which is phosphorylated in response to DSB formation, with MDC-1. Using these fusion proteins, the group demonstrated a dose dependent increase in luciferase activity following exposure to ionising radiation, which correlates with phosphorylation of the endogenous and luciferase-fused $\mathrm{H} 2 \mathrm{AX}$ proteins. In accordance with previous findings, they observe a rapid increase in luciferase activity 30 minutes after radiation exposure, which declines within 24 hours. However, they also unexpectedly observed a second peak in H2AX-MDC-1 interaction approximately 5-10 days after radiation exposure. By measuring caspase-3 activation and PARP cleavage they show that this second wave of luciferase activity correlates with tumor cell apoptosis, which is associated with the formation of numerous DSB.

\section{CONCLUSIONS}

Luciferase fragment complementation is a comparatively new technique which has specific strengths for use in preclinical cancer studies: it is cheap and safe; it is adaptable to low or high-throughput qualitative or quantitative research; it is readily adaptable to cell free, in vitro and in vivo studies; it is primed and reversible in nature; and it can be applied to a range of different cellular processes using various complementation or intein mediated methods.

At present, click beetle red luciferase is probably the most promising luciferase available for LFCAs. Although click beetle green has been shown to emit a stronger signal, click beetle red luciferase emits a comparatively strong signal relative to the other commonly used luciferases and its red emission spectrum is highly favorable for in vivo applications, particularly deep tissue othotopic imaging $[3,72]$. As the optical imaging field develops, it can be anticipated that the number of studies using click beetle red luciferase will increase, and that with this the body of knowledge surrounding the luciferase will grow considerably.

Recently, click beetle red luciferase has been used in combination with click beetle green luciferase to image multiple interactions in a single cell $[30,31]$. It is likely that these more complex LFCAs will increase in popularity as experimental demands and imaging systems develop. By combining LFCAs with resonance energy transfer methodologies, the quality and quantity of information extracted from a single experiment can be expected to increase even further. DragulescuAndrasi and colleagues have developed a red light emitting bioluminescent resonance energy transfer (BRET) technique to image deep tissue protein-protein 
interactions and Rebois et al. have combined luciferase and fluorescent complementation assays to image the association of 4 proteins in a single cell $[73,74]$. These experiments exploit the best features of these different imaging techniques: the use of a bioluminescent protein as a excitatory light source removes the need for external illumination, resulting in a lower background signal and consequently improved sensitivity; and the use of an acceptor fluorophore increases the signal intensity, enables the emission spectrum to be red shifted and enhances spatial resolution.

To date, luciferase fragment complementation has been applied to investigating various different aspects of cellular signaling. Innovative methods have been developed to investigate ligand binding, ligand pharmacology, transmembrane and intracellular receptor signaling, signal transduction, enzyme activation, and the presence of specific macromolecules within a cell. Given the infancy of the method, many of these studies have to a greater or lesser extent contained "proof-of-principle" elements, which aim to broaden the application of the technique rather than probe novel biological questions. However, these experiments have contributed greatly to establishing the validity and potential of the assay, and as the assay becomes widespread, it can be expected that it will be applied, in combination with other techniques, to more in-depth studies of biological and oncological importance.

One of the key areas which luciferase fragment complementation holds much promise is in the field of high-through put screening. This field is particularly relevant in cancer studies; as the number of available compound libraries increase and new therapeutic targets in cancer are identified the need for high-throughput screening technologies increases. Although relatively few in number, studies are now emerging in which LFCAs have been applied to screening large numbers of compounds or the validation of compounds identified by other screening methods $[42,64,68,75,76]$. Recently, a Gaussia luciferase based assay has also been developed for the validation of protein-protein interaction networks, which has been used to confirm a human papillomavirus interaction network identified using a yeast two-hybrid screen $[77,78]$.

Although luciferase fragment complementation is still a relatively new technique, it is clear that it has much to contribute to the field of cancer studies. The technique can be applied to qualitative investigations of cellular signaling or quantitative studies involving large data sets equally well. This enables the assay to be applied to almost all aspects of preclinical cancer studies, and as the field develops, the innovative applications of the assay are likely to increase.

\section{REFERENCES}

1. Hastings JW. Chemistries and colors of bioluminescent reactions: a review. Gene. 1996; 173(1 Spec No):5-11.

2. Hastings JW. Biological diversity, chemical mechanisms, and the evolutionary origins of bioluminescent systems. Journal of Molecular Evolution. 1983; 19(5):309-321.

3. Zhao H, Doyle TC, Coquoz O, Kalish F, Rice BW and Contag $\mathrm{CH}$. Emission spectra of bioluminescent reporters and interaction with mammalian tissue determine the sensitivity of detection in vivo. J Biomed Opt. 2005; 10(4):41210.

4. Weissleder R and Ntziachristos V. Shedding light onto live molecular targets. Nat Med. 2003; 9(1):123-128.

5. Tannous BA, Kim DE, Fernandez JL, Weissleder R and Breakefield XO. Codon-optimized Gaussia luciferase cDNA for mammalian gene expression in culture and in vivo. Molecular therapy : the journal of the American Society of Gene Therapy. 2005; 11(3):435-443.

6. Bhaumik S and Gambhir SS. Optical imaging of Renilla luciferase reporter gene expression in living mice. Proceedings of the National Academy of Sciences. 2002; 99(1):377-382.

7. Luker GD and Luker KE. Optical Imaging: Current Applications and Future Directions. J Nucl Med. 2008; 49(1):1-4.

8. Contag CH, Spilman SD, Contag PR, Oshiro M, Eames B, Dennery P, Stevenson DK and Benaron DA. Visualizing gene expression in living mammals using a bioluminescent reporter. Photochemistry and photobiology. 1997; 66(4):523-531.

9. Johnsson $\mathrm{N}$ and Varshavsky A. Split ubiquitin as a sensor of protein interactions in vivo. Proc Natl Acad Sci U S A. 1994; 91(22): 10340-10344.

10. Pelletier JN, Campbell-Valois FX and Michnick SW. Oligomerization domain-directed reassembly of active dihydrofolate reductase from rationally designed fragments. Proc Natl Acad Sci U S A. 1998; 95(21):12141-12146.

11. Rossi F, Charlton CA and Blau HM. Monitoring proteinprotein interactions in intact eukaryotic cells by betagalactosidase complementation. Proc Natl Acad Sci U S A. 1997; 94(16):8405-8410.

12. Paulmurugan R, Umezawa $Y$ and Gambhir SS. Noninvasive imaging of protein-protein interactions in living subjects by using reporter protein complementation and reconstitution strategies. Proceedings of the National Academy of Sciences of the United States of America. 2002; 99(24):15608-15613.

13. Ozawa T, Kaihara A, Sato M, Tachihara K and Umezawa Y. Split luciferase as an optical probe for detecting proteinprotein interactions in mammalian cells based on protein splicing. Anal Chem. 2001; 73(11):2516-2521.

14. Badran AH, Furman JL, Ma AS, Comi TJ, Porter JR and Ghosh I. Evaluating the global $\mathrm{CpG}$ methylation status of 
native DNA utilizing a bipartite split-luciferase sensor. Anal Chem. 2011; 83(18):7151-7157.

15. Huang X, Narayanaswamy R, Fenn K, Szpakowski S, Sasaki C, Costa J, Blancafort P and Lizardi PM. Sequencespecific biosensors report drug-induced changes in epigenetic silencing in living cells. DNA and cell biology. 2012; 31 Suppl 1:S2-10.

16. Furman JL, Badran AH, Ajulo O, Porter JR, Stains CI, Segal DJ and Ghosh I. Toward a general approach for RNA-templated hierarchical assembly of split-proteins. J Am Chem Soc. 2010; 132(33):11692-11701.

17. Zhang L, Lee KC, Bhojani MS, Khan AP, Shilman A, Holland EC, Ross BD and Rehemtulla A. Molecular imaging of Akt kinase activity. Nat Med. 2007; 13(9):11141119.

18. Endoh T, Mie M, Funabashi H, Sawasaki T, Endo Y and Kobatake E. Construction of Intramolecular Luciferase Complementation Probe for Detecting Specific RNA. Bioconjugate Chem. 2007; 18(3):956-962.

19. Taneoka A, Sakaguchi-Mikami A, Yamazaki T, Tsugawa $\mathrm{W}$ and Sode K. The construction of a glucose-sensing luciferase. Biosens Bioelectron. 2009; 25(1):76-81.

20. Coppola JM, Ross BD and Rehemtulla A. Noninvasive Imaging of Apoptosis and Its Application in Cancer Therapeutics. Clin Cancer Res. 2008; 14(8):2492-2501.

21. Shekhawat SS, Porter JR, Sriprasad A and Ghosh I. An autoinhibited coiled-coil design strategy for split-protein protease sensors. J Am Chem Soc. 2009; 131(42):1528415290 .

22. Paulmurugan R and Gambhir SS. Firefly luciferase enzyme fragment complementation for imaging in cells and living animals. Anal Chem. 2005; 77(5):1295-1302.

23. de Wet JR, Wood KV, Helinski DR and DeLuca M. Cloning of firefly luciferase cDNA and the expression of active luciferase in Escherichia coli. Proc Natl Acad Sci U S A. 1985; 82(23):7870-7873.

24. de Wet JR, Wood KV, DeLuca M, Helinski DR and Subramani S. Firefly luciferase gene: structure and expression in mammalian cells. Mol Cell Biol. 1987; 7(2):725-737.

25. Conti E, Franks NP and Brick P. Crystal structure of firefly luciferase throws light on a superfamily of adenylateforming enzymes. Structure. 1996; 4(3):287-298.

26. Luker KE, Smith MC, Luker GD, Gammon ST, PiwnicaWorms $\mathrm{H}$ and Piwnica-Worms D. Kinetics of regulated protein-protein interactions revealed with firefly luciferase complementation imaging in cells and living animals. Proc Natl Acad Sci U S A. 2004; 101(33):12288-12293.

27. Paulmurugan $\mathrm{R}$ and Gambhir SS. Combinatorial library screening for developing an improved split-firefly luciferase fragment-assisted complementation system for studying protein-protein interactions. Anal Chem. 2007; 79(6):23462353.

28. Paulmurugan R, Massoud TF, Huang $\mathrm{J}$ and Gambhir
SS. Molecular imaging of drug-modulated proteinprotein interactions in living subjects. Cancer Res. 2004; 64(6):2113-2119.

29. Remy I and Michnick SW. A highly sensitive proteinprotein interaction assay based on Gaussia luciferase. Nat Methods. 2006; 3(12):977-979.

30. Villalobos V, Naik S, Bruinsma M, Dothager RS, Pan MH, Samrakandi M, Moss B, Elhammali A and Piwnica-Worms D. Dual-color click beetle luciferase heteroprotein fragment complementation assays. Chem Biol. 2010; 17(9):10181029.

31. Hida N, Awais M, Takeuchi M, Ueno N, Tashiro M, Takagi C, Singh T, Hayashi M, Ohmiya Y and Ozawa T. High-Sensitivity Real-Time Imaging of Dual ProteinProtein Interactions in Living Subjects Using Multicolor Luciferases. PLoS ONE. 2009; 4(6):e5868.

32. Paulmurugan R, Tamrazi A, Massoud TF, Katzenellenbogen JA and Gambhir SS. In vitro and in vivo molecular imaging of estrogen receptor alpha and beta homo- and heterodimerization: exploration of new modes of receptor regulation. Mol Endocrinol. 2011; 25(12):2029-2040.

33. Hattori M, Haga S, Takakura H, Ozaki M and Ozawa T. Sustained accurate recording of intracellular acidification in living tissues with a photo-controllable bioluminescent protein. Proc Natl Acad Sci U S A. 2013; 110(23):93329337.

34. Ohmuro-Matsuyama Y, Chung $\mathrm{CI}$ and Ueda $\mathrm{H}$. Demonstration of protein-fragment complementation assay using purified firefly luciferase fragments. BMC biotechnology. 2013; 13:31.

35. Stefan E, Aquin S, Berger N, Landry CR, Nyfeler B, Bouvier M and Michnick SW. Quantification of dynamic protein complexes using Renilla luciferase fragment complementation applied to protein kinase A activities in vivo. Proceedings of the National Academy of Sciences. 2007; 104(43):16916-16921.

36. $\mathrm{Hu} \mathrm{CD}$, Chinenov Y and Kerppola TK. Visualization of interactions among bZIP and Rel family proteins in living cells using bimolecular fluorescence complementation. Mol Cell. 2002; 9(4):789-798.

37. Magliery TJ, Wilson CG, Pan W, Mishler D, Ghosh I, Hamilton $\mathrm{AD}$ and Regan L. Detecting protein-protein interactions with a green fluorescent protein fragment reassembly trap: scope and mechanism. J Am Chem Soc. 2005; 127(1):146-157.

38. Riely GJ, Pao W, Pham D, Li AR, Rizvi N, Venkatraman ES, Zakowski MF, Kris MG, Ladanyi M and Miller VA. Clinical course of patients with non-small cell lung cancer and epidermal growth factor receptor exon 19 and exon 21 mutations treated with gefitinib or erlotinib. Clin Cancer Res. 2006; 12 (3 Pt 1):839-844.

39. Franklin WA, Veve R, Hirsch FR, Helfrich BA and Bunn PA, Jr. Epidermal growth factor receptor family in lung cancer and premalignancy. Seminars in oncology. 2002; 
29(1 Suppl 4):3-14.

40. Ross JS, Slodkowska EA, Symmans WF, Pusztai L, Ravdin PM and Hortobagyi GN. The HER-2 Receptor and Breast Cancer: Ten Years of Targeted Anti-HER-2 Therapy and Personalized Medicine. The Oncologist. 2009; 14(4):320368.

41. Yang KS, Ilagan MX, Piwnica-Worms D and Pike LJ. Luciferase fragment complementation imaging of conformational changes in the epidermal growth factor receptor. J Biol Chem. 2009; 284(12):7474-7482.

42. Yang RY, Yang KS, Pike LJ and Marshall GR. Targeting the dimerization of epidermal growth factor receptors with small-molecule inhibitors. Chemical biology \& drug design. 2010; 76(1):1-9.

43. Macdonald-Obermann JL, Piwnica-Worms D and Pike LJ. Mechanics of EGF receptor/ErbB2 kinase activation revealed by luciferase fragment complementation imaging. Proc Natl Acad Sci U S A. 2012; 109(1):137-142.

44. Wolf F, Li W, Li F and Li CY. Non-invasive, quantitative monitoring of hyperthermia-induced EGFR activation in xenograft tumours. International journal of hyperthermia : the official journal of European Society for Hyperthermic Oncology, North American Hyperthermia Group. 2011; 27(5):427-434.

45. Wolf F, Li W, Li F and Li CY. Novel luciferase-based reporter system to monitor activation of ErbB2/Her2/neu pathway noninvasively during radiotherapy. International journal of radiation oncology, biology, physics. 2011; 79(1):233-238.

46. Li W, Li F, Huang Q, Frederick B, Bao S and Li C-Y. Noninvasive Imaging and Quantification of Epidermal Growth Factor Receptor Kinase Activation In vivo. Cancer Res. 2008; 68(13):4990-4997.

47. Khan AP, Contessa JN, Nyati MK, Ross BD and Rehemtulla A. Molecular imaging of epidermal growth factor receptor kinase activity. Analytical biochemistry. 2011; 417(1):5764.

48. Kim SB, Awais M, Sato M, Umezawa Y and Tao H. Integrated molecule-format bioluminescent probe for visualizing androgenicity of ligands based on the intramolecular association of androgen receptor with its recognition Peptide. Anal Chem. 2007; 79(5):1874-1880.

49. Kim SB, Otani Y, Umezawa Y and Tao H. Bioluminescent Indicator for Determining Protein-Protein Interactions Using Intramolecular Complementation of Split Click Beetle Luciferase. Anal Chem. 2007; 79(13):4820-4826.

50. Kim SB, Ozawa T, Watanabe S and Umezawa Y. Highthroughput sensing and noninvasive imaging of protein nuclear transport by using reconstitution of split Renilla luciferase. Proc Natl Acad Sci U S A. 2004; 101(32):1154211547.

51. Kim SB, Kanno A, Ozawa T, Tao H and Umezawa Y. Nongenomic Activity of Ligands in the Association of Androgen Receptor with Src. ACS Chem Biol. 2007;
2(7):484-492.

52. Lake MC, Nguyen QD, Ali S and Aboagye EO. Development of a novel molecular sensor for imaging estrogen receptor-coactivator protein-protein interactions. PLoS ONE. 2012; 7(8):e44160.

53. Paulmurugan $\mathrm{R}$ and Gambhir SS. An intramolecular folding sensor for imaging estrogen receptor-ligand interactions. Proc Natl Acad Sci U S A. 2006; 103(43):15883-15888.

54. Paulmurugan R, Tamrazi A, Katzenellenbogen JA, Katzenellenbogen BS and Gambhir SS. A human estrogen receptor (ER)alpha mutation with differential responsiveness to nonsteroidal ligands: novel approaches for studying mechanism of ER action. Mol Endocrinol. 2008; 22(7):1552-1564.

55. Luker KE, Gupta $M$ and Luker GD. Imaging chemokine receptor dimerization with firefly luciferase complementation. The FASEB Journal. 2009; 23(3):823834.

56. Luker KE, Gupta $M$ and Luker GD. Imaging CXCR4 Signaling with Firefly Luciferase Complementation. Anal Chem. 2008; 80(14):5565-5573.

57. Luker KE, Gupta M, Steele JM, Foerster BR and Luker GD. Imaging ligand-dependent activation of CXCR7. Neoplasia (New York, NY). 2009; 11(10):1022-1035.

58. Salomonnson E, Stacer AC, Ehrlich A, Luker KE and Luker GD. Imaging CXCL12-CXCR4 signaling in ovarian cancer therapy. PLoS ONE. 2013; 8(1):e51500.

59. Ray P, Lewin SA, Mihalko LA, Schmidt BT, Luker KE and Luker GD. Noninvasive imaging reveals inhibition of ovarian cancer by targeting CXCL12-CXCR4. Neoplasia (New York, NY). 2011; 13(12):1152-1161.

60. Luker KE, Mihalko LA, Schmidt BT, Lewin SA, Ray P, Shcherbo D, Chudakov DM and Luker GD. In vivo imaging of ligand receptor binding with Gaussia luciferase complementation. Nat Med. 2012; 18(1):172-177.

61. Ray P, Lewin SA, Mihalko LA, Lesher-Perez SC, Takayama S, Luker KE and Luker GD. Secreted CXCL12 (SDF-1) forms dimers under physiological conditions. The Biochemical journal. 2012; 442(2):433-442.

62. Ataei F, Torkzadeh-Mahani M and Hosseinkhani S. A novel luminescent biosensor for rapid monitoring of IP3 by splitluciferase complementary assay. Biosens Bioelectron. 2013; 41:642-648.

63. Takeuchi M, Nagaoka Y, Yamada T, Takakura H and Ozawa T. Ratiometric bioluminescence indicators for monitoring cyclic adenosine 3',5'-monophosphate in live cells based on luciferase-fragment complementation. Anal Chem. 2010; 82(22):9306-9313.

64. Chan CT, Paulmurugan R, Reeves RE, Solow-Cordero D and Gambhir SS. Molecular imaging of phosphorylation events for drug development. Molecular imaging and biology : MIB : the official publication of the Academy of Molecular Imaging. 2009; 11(3):144-158.

65. Nyati S, Ranga R, Ross BD, Rehemtulla A and Bhojani 
MS. Molecular imaging of glycogen synthase kinase-3beta and casein kinase-1alpha kinases. Analytical biochemistry. 2010; 405(2):246-254.

66. Fan-Minogue H, Cao Z, Paulmurugan R, Chan CT, Massoud TF, Felsher DW and Gambhir SS. Noninvasive molecular imaging of c-Myc activation in living mice. Proc Natl Acad Sci U S A. 2010; 107(36):15892-15897.

67. Xie W, Pao C, Graham T, Dul E, Lu Q, Sweitzer TD, Ames RS and Li H. Development of a cell-based high throughput luciferase enzyme fragment complementation assay to identify nuclear-factor-e2-related transcription factor 2 activators. Assay and drug development technologies. 2012; 10(6):514-524.

68. Ramkumar KM, Sekar TV, Foygel K, Elango B and Paulmurugan R. Reporter Protein Complementation Imaging Assay to Screen and Study Nrf2 Activators in Cells and Living Animals. Anal Chem. 2013.

69. Leng W, Pang X, Xia H, Li M, Chen L, Tang Q, Yuan D, Li R, Li L, Gao F and Bi F. Novel split-luciferasebased genetically encoded biosensors for noninvasive visualization of Rho GTPases. PLoS ONE. 2013; 8(4):e62230.

70. Andou T, Endoh T, Mie M and Kobatake E. RNA detection using peptide-inserted Renilla luciferase. Analytical and bioanalytical chemistry. 2009; 393(2):661-668.

71. Li W, Li F, Huang Q, Shen J, Wolf F, He Y, Liu X, Hu YA, Bedford JS and Li CY. Quantitative, noninvasive imaging of radiation-induced DNA double-strand breaks in vivo. Cancer Res. 2011; 71(12):4130-4137.

72. Miloud T, Henrich C and Hammerling GJ. Quantitative comparison of click beetle and firefly luciferases for in vivo bioluminescence imaging. J Biomed Opt. 2007; 12(5):054018

73. Dragulescu-Andrasi A, Chan CT, De A, Massoud TF and Gambhir SS. Bioluminescence resonance energy transfer (BRET) imaging of protein-protein interactions within deep tissues of living subjects. Proceedings of the National Academy of Sciences. 2011; 108(29):12060-12065.

74. Rebois RV, Robitaille M, Petrin D, Zylbergold P, Trieu P and Hebert TE. Combining protein complementation assays with resonance energy transfer to detect multipartner protein complexes in living cells. Methods. 2008; 45(3):214-218.

75. Chan CT, Reeves RE, Geller R, Yaghoubi SS, Hoehne A, Solow-Cordero DE, Chiosis G, Massoud TF, Paulmurugan $\mathrm{R}$ and Gambhir SS. Discovery and validation of smallmolecule heat-shock protein 90 inhibitors through multimodality molecular imaging in living subjects. Proc Natl Acad Sci U S A. 2012; 109(37):E2476-2485.

76. Li BX and Xiao X. Discovery of a small-molecule inhibitor of the KIX-KID interaction. Chembiochem. 2009; 10(17):2721-2724.

77. Neveu G, Cassonnet P, Vidalain PO, Rolloy C, Mendoza J, Jones L, Tangy F, Muller M, Demeret C, Tafforeau L, Lotteau V, Rabourdin-Combe C, Trave G, Dricot A,
Hill DE, Vidal M, et al. Comparative analysis of virushost interactomes with a mammalian high-throughput protein complementation assay based on Gaussia princeps luciferase. Methods. 2012; 58(4):349-359.

78. Cassonnet P, Rolloy C, Neveu G, Vidalain PO, Chantier T, Pellet J, Jones L, Muller M, Demeret C, Gaud G, Vuillier F, Lotteau V, Tangy F, Favre M and Jacob Y. Benchmarking a luciferase complementation assay for detecting protein complexes. Nat Methods. 2011; 8(12):990-992.

79. Paulmurugan $\mathrm{R}$ and Gambhir SS. Monitoring proteinprotein interactions using split synthetic renilla luciferase protein-fragment-assisted complementation. Anal Chem. 2003; 75(7):1584-1589.

80. Kaihara A, Kawai Y, Sato M, Ozawa T and Umezawa Y. Locating a protein-protein interaction in living cells via split Renilla luciferase complementation. Anal Chem. 2003; 75(16):4176-4181.

81. Misawa N, Kafi AK, Hattori M, Miura K, Masuda K and Ozawa T. Rapid and high-sensitivity cell-based assays of protein-protein interactions using split click beetle luciferase complementation: an approach to the study of G-protein-coupled receptors. Anal Chem. 2010; 82(6):25522560 . 